\title{
Enhanced polyhydroxyalkanoate (PHA) production from the organic fraction of municipal solid waste by using mixed microbial culture
}

Bianca Colombo ${ }^{1}$, Francesca Favini ${ }^{1}$, Barbara Scaglia' ${ }^{1}$ Tommy Pepè Sciarria', Giuliana D'Imporzano', Michele Pognani ${ }^{1}$, Anna Alekseeva ${ }^{2}$, Giorgio Eisele ${ }^{2}$, Cesare Cosentino ${ }^{3}$ and Fabrizio Adani ${ }^{1 *}$ (i)

\begin{abstract}
Background: In Europe, almost 87.6 million tonnes of food waste are produced. Despite the high biological value of food waste, traditional management solutions do not consider it as a precious resource. Many studies have reported the use of food waste for the production of high added value molecules. Polyhydroxyalkanoates (PHAs) represent a class of interesting bio-polyesters accumulated by different bacterial cells, and has been proposed for production from the organic fraction of municipal solid waste (OFMSW). Nevertheless, until now, no attention has been paid to the entire biological process leading to the transformation of food waste to organic acids $(\mathrm{OA})$ and then to PHA, getting high PHA yield per food waste unit. In particular, the acid-generating process needs to be optimized, maximizing OA production from OFMSW. To do so, a pilot-scale Anaerobic Percolation Biocell Reactor (100 L in volume) was used to produce an OA-rich percolate from OFMSW which was used subsequently to produce PHA.
\end{abstract}

Results: The optimized acidogenic process resulted in an OA production of $151 \mathrm{~g} \mathrm{~kg}^{-1}$ from fresh OFMSW. The subsequent optimization of PHA production from OA gave a PHA production, on average, of $223 \pm 28 \mathrm{~g} \mathrm{~kg}^{-1}$ total OA fed. Total mass balance indicated, for the best case studied, a PHA production per OFMSW weight unit of $33.22 \pm 4.2 \mathrm{~g} \mathrm{~kg}^{-1}$ from fresh OFMSW, corresponding to $114.4 \pm 14.5 \mathrm{~g} \mathrm{~kg}^{-1}$ of total solids from OFMSW. PHA composition revealed a hydroxybutyrate/hydroxyvalerate (\%) ratio of 53/47 and Mw of $8 \cdot 10^{5} \mathrm{kDa}$ with a low polydispersity index, i.e. 1.4.

Conclusions: This work showed how by optimizing acidic fermentation it could be possible to get a large amount of OA from OFMSW to be then transformed into PHA. This step is important as it greatly affects the total final PHA yield. Data obtained in this work can be useful as the starting point for considering the economic feasibility of PHA production from OFMSW by using mixed culture.

Keywords: Aerobic dynamic feeding strategy, Anaerobic percolation biocell reactor, Mixed microbial culture, Municipal solid waste, Polyhydroxyalkanoate, Sequencing batch reactor

\section{Background}

Food waste (FW) is defined as the organic material produced for human consumption and discarded, lost or

\footnotetext{
*Correspondence: fabrizio.adani@unimi.it

1 Gruppo Ricicla labs-DiSAA-Università degli Studi di Milano, Via Celoria 2, 20133 Milan, Italy

Full list of author information is available at the end of the article
}

degraded, primarily at manufacturing, retail and consumption stages [1]. In Europe, almost 87.6 million tonnes of FW are produced annually [2]. These wastes are characterized by both high moisture and high biodegradability, so FW creates adverse environmental impacts if landfilled (odours, fires, volatile organic compounds, groundwater contamination by leachate, global climate changes, etc.) and also, high disposal costs (88-144 \$ 
tonne ${ }^{-1}$ ) [1]. European and national legislation have focused on avoiding FW landfilling by treating it through a thermal process (incineration) or, more frequently, by biological processes (anaerobic digestion and composting) to be carried out on the separately collected organic fraction of municipal solid waste (OFMSW) [3]. Despite the high biological value of FW, traditional management solutions do not consider it as a precious resource, adding only a small amount of value to the final product, i.e. $60-150 \$$ tonne $^{-1}$ of biomass for electricity production and 5-10 $\$$ tonne $^{-1}$ of biomass for compost production [4]. Therefore, supporting these activities generally requires government contributions or high tariffs for citizens, e.g. in Italy the waste tariff increased by $70 \%$ in the last 10 years.

FW is an organic matrix rich in valuable molecules such as starch, cellulose, hemicellulose, lignin, proteins, lipids and organic acids that could be managed in a more sustainably economic way by using it as a raw material for bulk chemicals production [4]. Many studies have reported the use of FW for the production of high added value molecules such as lactic acid, citric acid, succinic acid, single cell oils, enzymes and polymers [5], an approach which is more financially rewarding in comparison with compost and biomethane production (1000 \$ tonne $\mathrm{e}^{-1}$ of biomass for bulk chemicals production from FW) [6].

Among the wide varieties of bio-products obtainable from FW are the polyhydroxyalkanoates (PHAs), a class of interesting bio-polyesters accumulated by different bacterial cells under the form of granules inside the cytoplasm. PHAs are completely biodegradable and are mainly produced starting from renewable sources; their chief interesting property is their mechanical behaviour that make them comparable to common plastics [7]. Microbial PHA production can be carried out by using either pure or mixed microbial cultures (MMC). MMC with high PHA accumulation capacity have been suggested as a solution for reducing the high maintenance costs of pure cultures. Many studies related to PHA production by MMC have performed both selection of PHA-storing cultures and PHA accumulation by using just $\mathrm{OA}$ as substrates, since they are the direct metabolic precursors of PHA [7], while PHA production carried out by using pure cultures allows the employment of both OA and simple sugars as carbon sources. Working with mixed microbial cultures, simple sugars are not recommended as they can be used by the culture for the production of other molecules (i.e. glycogen), reducing the final PHA production yield $[8,9]$. Given the high costs of synthetic OA, agro-industrial wastes, such as molasses, cheese whey, olive oil mill effluent, palm oil mill effluent, candy bar factory wastewater and many other waste streams [10-14], can be treated by acidic fermentation to produce OA which can then be transformed into PHA by MMC.

Complex wastes, such as OFMSW, have been reported in the literature to be used as substrates for PHA production by MMC [15-18]. These studies focused attention on PHA production from OA obtained by the fermentation of OFMSW, but until now, no attention has been paid to the entire process leading to the transformation of OFMSW to OA and then to PHA, i.e. to obtain overall estimates of PHA yield based on OFMSW weight unit used. These data, together with those showing the scientific feasibility in transforming organic waste into PHA, are important to estimate the effective economic sustainability of PHA production from OFMSW.

In this work, a two-stage approach, i.e. OA production from OFMSW and subsequent PHA biosynthesis from $\mathrm{OA}$, is proposed.

Optimization of the acidic fermentation of OFMSW was carried out in order to exploit the biological potential of this complex matrix, obtaining a percolate rich in OA used subsequently as the substrate to produce PHA by employing MMC. Global mass balance of the process performed was achieved as well as the complete characterization of the polymer obtained.

\section{Methods}

\section{Percolates production from OFMSW Organic fraction of municipal solid waste collection}

The source-separated OFMSW coming from street bin containers was collected at a full-scale composting plant located in northern Italy. Collection was done by following the quartering method: in brief, the OFMSW was sampled at different points of the whole mass (500 kg wet weight - w.w. $-\times 3$ times); then the collected waste was mixed, quartered and sub-sampled until a final sample of about $300 \mathrm{~kg}$ w.w. material was reached. OFMSW was stored at $4{ }^{\circ} \mathrm{C}$ before the trials were set up. A representative sample of approximately $30 \mathrm{~kg}$, obtained by mixing sub-samples of about $5 \mathrm{~kg}$ each taken randomly from sampled material, was dried and crushed to $2 \mathrm{~mm}$ and then used to perform analytical analyses.

The bulking agent (shredded wood) from the same plant was also collected following a similar approach.

Liquid digestate, used to irrigate OFMSW during dry anaerobic fermentation (see later), was collected directly from a continuously stirred tank reactor anaerobic digester (CSTR-AD) plant fed with OFMSW, located in northern Italy and previously described [19]. Digestate was collected from this plant in large quantities from the 
discharge pipe system of the post-digester after 30 days of retention time (HRT).

\section{Experimental apparatus}

The acidogenesis (SSAD) trials were carried out by developing a pilot-scale anaerobic percolation biocell reactor (APBR) that was made up of an insulated vertical cylinder (100 L of volume) of PVC material with a hermetic cap. Inside the reactor, there was a stainless steel basket with holes at the bottom, into which OFMSW was introduced from the APBR cap, as well as the digestate used to irrigate the organic wastes (Fig. 1). From the bottom of the APBR, the percolate generated daily due to digestate irrigation was extracted and weighed. Digestate irrigation was used to buffer the acidity produced during OFMSW fermentation and to remove OA produced in the APBR. This encouraged high hydrolysis performance from the organic waste, which is the limiting step in producing large amounts of OA from organic substrates [20, 21]. Moreover, large-scale OA production becomes toxic for methanogenic bacteria, limiting methane production during the trials.

\section{Experimental setup}

Three different percolation trials were carried out. For all of them, fresh OFMSW (85\% w.w.) and bulking agent (chopped green waste material) (15\% w.w.) were mixed just before reactor filling to avoid clogging problems in the APBR, allowing the percolation. For each trial, the APBR was filled with about $50 \mathrm{~kg}$ of mixture (OFMSWmix-in).

The OFMSWmix-in in the APBR was irrigated continuously by using the liquid digestate obtained from the full-scale CSTR-AD plant in order to optimize OFMSW hydrolysis and subsequent acidogenesis fermentation to produce OA. Anaerobic hydrolysis and acidic fermentation lasted for 21 days for each trial performed. During this time, irrigation with the liquid digestate (previously heated to $55{ }^{\circ} \mathrm{C}$ ) was done continuously by using a peristaltic pump, adopting an OFMSWmix-in/digestate ratio of 1:0.45 kg kg $\mathrm{kg}^{-1}$ (flow rate of $0.02 \mathrm{~L} \mathrm{~h}^{-1} \mathrm{~kg}^{-1}$ OFMSW $_{\text {w.w. }}$ ) for the first trial (Trial 1), $1: 0.9 \mathrm{~kg} \mathrm{~kg}^{-1}$ (flow rate of $0.04 \mathrm{~L} \mathrm{~h}^{-1} \mathrm{~kg}^{-1} \mathrm{OFMSW}_{\text {w.w. }}$ ) for the second trial (Trial 2), and of $1: 1.8 \mathrm{~kg} \mathrm{~kg}^{-1}$ (flow rate of $0.08 \mathrm{~L} \mathrm{~h}^{-1} \mathrm{~kg}^{-1}$ OFMSW $_{\text {w.w. }}$ ) (day 1-8) and of $1: 0.9 \mathrm{~kg} \mathrm{~kg}^{-1}$ (flow rate

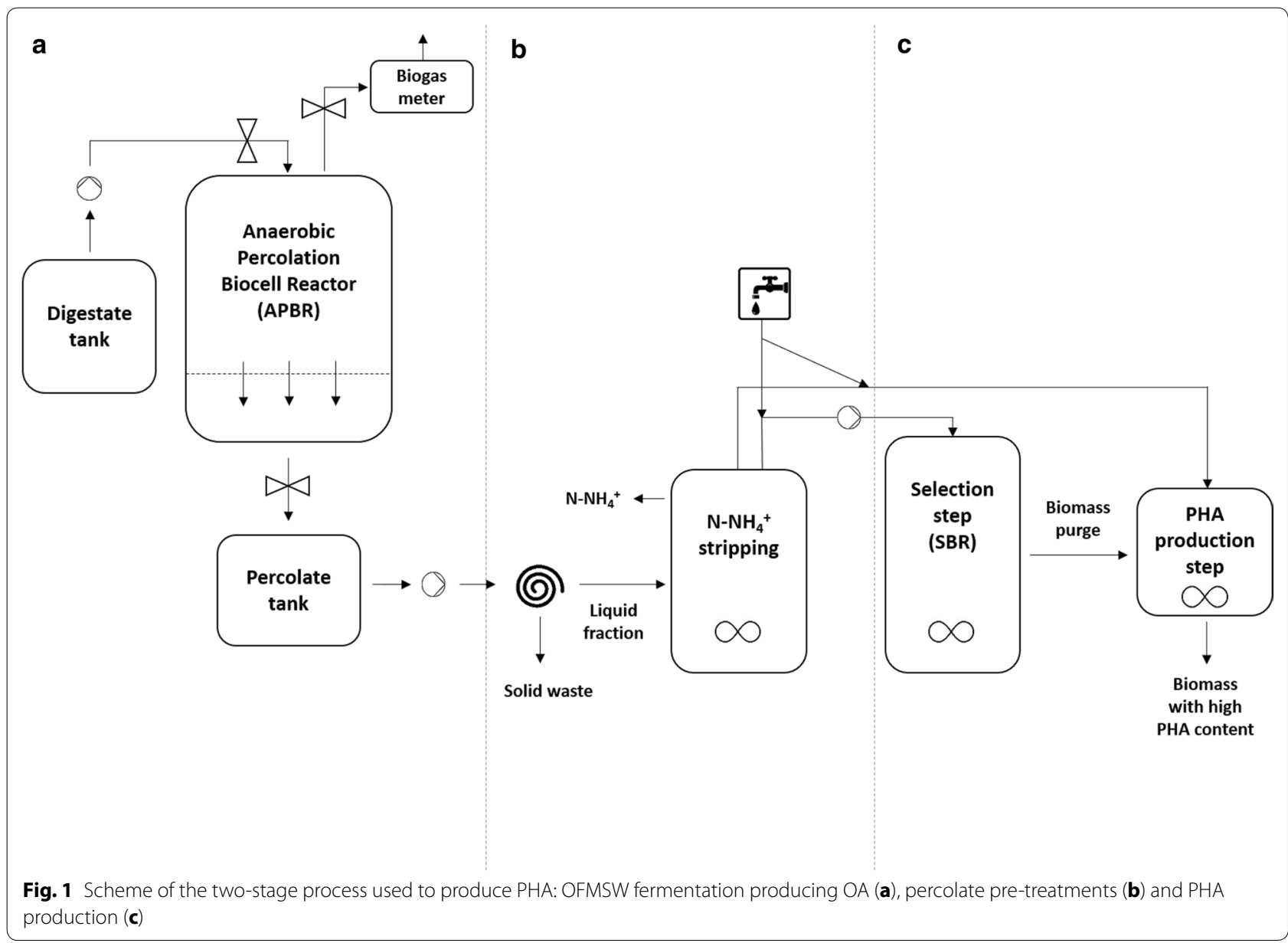


of $0.04 \mathrm{~L} \mathrm{~h}^{-1} \mathrm{~kg}^{-1} \mathrm{OFMSW}_{\text {w.w. }}$ ) (day 9-21) for the third trial (Trial 3), respectively. The daily-generated percolates were collected from the bottom of the APBR, quantified and mixed together to get a final mixed percolate sample for each trial.

\section{Percolates treatment before PHA production}

The three percolates obtained from anaerobic acidic fermentation trials were submitted to two pre-treatments before their use for polyhydroxyalkanoate (PHA) production. The first pre-treatment was to centrifuge the percolates at 20,000 $g$ for $15 \mathrm{~min}$, reducing suspended organic carbon from percolates. Supernatants obtained underwent a second pre-treatment adopted to remove ammonia by stripping. This step was performed by bringing supernatant-pH to 11 by adding $6-\mathrm{mol} \mathrm{L}^{-1} \mathrm{KOH}$ and stirring it (magnetic stirring at $200 \mathrm{rpm}$ ) under the hood until a final C:N close to 10 was reached [11]. Then ammonia stripping was stopped and the $\mathrm{pH}$ was brought again to the initial value of 8 by using $3 \mathrm{~mol} \mathrm{~L}^{-1} \mathrm{H}_{2} \mathrm{SO}_{4}$. Ammonia stripped was not trapped at lab scale and it was not considered in this work. Obviously, this step needs to be considered and further studied on a larger scale.

After pre-treatments, the three supernatants were diluted with deionized water, to produce a final COD content close to $1300 \mathrm{mg} \mathrm{L}^{-1}$ [11]. These OFMSWderived supernatants (OFMSW-supernatants ${ }_{\text {in }}$ ) were used for subsequent inoculum selection.

Substrates (OFMSW-supernatants acc. $_{\text {) }}$ used for PHA accumulation tests were derived from percolates that had undergone the same treatments shown for those destined for the inoculum selection. Three OFMSW-supernatant$s_{\text {acc. }}$ were obtained but, in this case, the ammonia content was lower than those reported for OFMSW-supernatant$\mathrm{s}_{\mathrm{in}}$, since it has been reported that $\mathrm{N}$ starvation can determine a greater conversion of carbon into PHA because of cell growth limitation [22]. Moreover, OFMSW-supernatants $_{\text {acc, }}$ were less diluted, giving a final COD concentration of about $7500 \mathrm{mg} \mathrm{L}^{-1}$, in order to avoid an excessive dilution of the biomass in the accumulation reactor [10].

\section{Inoculum production and PHA-producing bacteria enrichment}

The enrichment of PHA-producing bacteria was performed by using an inoculum constituted by an activated sludge ( $5 \mathrm{~g}$ total suspended solids $\mathrm{L}^{-1}$ ) collected from the secondary sedimentation tank of a wastewater treatment plant $\left(5.2 \times 10^{5}\right.$ equivalent inhabitants) located at Peschiera Borromeo (Milan, Italy).

The enrichment in PHA-producing bacteria was carried out in a Sequencing Batch Reactor (SBR) with a working volume of $800 \mathrm{~mL}$, applying an aerobic dynamic feeding (ADF) strategy [11]. In brief, the SBR cycle length was of $12 \mathrm{~h}$, consisting of four discrete phases: (1) influent filling ( $4 \mathrm{~min}),(2)$ aeration (675 min), (3) settling (40 $\mathrm{min}$ ) and (4) withdrawal of the exhausted effluent (5 min), with 1 day of hydraulic retention time (HRT) and 5 days of Sludge Retention Time (SRT), keeping the temperature at $25^{\circ} \mathrm{C}$ and the $\mathrm{pH}$ at 8.8 , this latter controlled automatically by adding $1 \mathrm{~mol} \mathrm{~L}^{-1} \mathrm{HCl}$. Aeration and agitation were provided by supplying air at $6 \mathrm{~L} \mathrm{~min}^{-1}$ and stirring set at $110 \mathrm{rpm}$. Pumping, aeration and stirring were automatically controlled.

The selection process lasted for 3 months; for each month, a different pre-treated supernatant was used as substrate: OFMSW-supernatant ${ }_{\text {in }} 1$, OFMSW-supernatant $_{\text {in }} 2$ and OFMSW-supernatant in 3 , respectively, for the first, second and third month of selection.

The selection trend was monitored by determining the duration of the feast phase achievable by using the dissolved oxygen (DO) concentration in the selection media [10], measured by an optical probe (FDO 925, WTW, Germany).

In particular, the feast (h)-to-famine (h) ratio (F/F ratio) was calculated as the ratio between the lengths in hours of the two phases. For a correct selection of PHAstoring bacteria, the $\mathrm{F} / \mathrm{F}$ ratio had to be equal or less than 0.33 [23]. To carry out the selection of PHA-accumulating bacteria, $400 \mathrm{~mL}$ of activated sludge was used as the inoculum feed for each cycle, with $400 \mathrm{~mL}$ of OFMSWsupernatant $_{\text {in }}$. Organic Loading Rate (OLR) was kept close to $1300 \mathrm{mg} \mathrm{COD} \mathrm{L}^{-1}$ day $^{-1}$ and the $\mathrm{C}: \mathrm{N}: \mathrm{P}$ ratio was of about 100:13:0.4 mol C: mmole N: mmole P. Every month, two cycles were monitored in order to evaluate the performance of the selected culture. In particular, monitoring was performed between cycles 31 and cycle 45 since it was reported that the cultures reach stability after three SRTs from the beginning of the trial (cycle 31) [24].

\section{PHA accumulation}

The ability of the MMC to accumulate PHA was assessed by fed-batch assays carried out in a $300-\mathrm{mL}$ working volume glass reactor, with continuous aeration and stirring. These assays consisted of feeding the substrate to $160 \mathrm{~mL}$ of enriched culture (at least 3 SRTs from the beginning of the selection) [24] adopting a pulse-wise feeding method. The assays were monitored continuously by measuring the concentration of the dissolved oxygen in the accumulation media [10]. In particular, substrate (OFMSWsupernatant $t_{\mathrm{acc}}$ ) was fed to the reactor when DO showed a strong increase [10]. Total C dosed was calculated taking into account that the ratio of the carbon to the microorganisms had to be the same as that inside the selection reactor. The assays were stopped when no DO variation followed the substrate feeding. 
For the accumulation tests, the operating conditions used were those adopted in the selection reactor, i.e. temperature of $25{ }^{\circ} \mathrm{C}$, aeration of $6 \mathrm{~L} \mathrm{~min}^{-1}$ and stirring at $110 \mathrm{rpm}$.

The biomass from the selection process was submitted to accumulation tests using the same substrate as the carbon source; every month, two accumulation trials were performed in duplicate, between the cycles 31 and 45 .

\section{PHA extraction}

The biomass collected after PHA accumulation tests was centrifuged at $8000 \mathrm{~g}$ for $15 \mathrm{~min}$, washed with $0.9 \%$ sodium chloride solution and centrifuged again at $8000 \mathrm{~g}$ for $20 \mathrm{~min}$. The pellet obtained was lyophilized and then suspended in chloroform (in a ratio of ca. $40 \mathrm{~mL} \mathrm{CHCl}_{3}$ $\mathrm{g}^{-1}$ dried cells) and left to dissolve for a period of 3 days at $37{ }^{\circ} \mathrm{C}[10]$. The solution was then filtered to remove all undissolved material. The extracted PHA in chloroform was then precipitated by the addition of 5 volumes of methanol and allowed to settle down for $30 \mathrm{~min}$ [25]. The white precipitate formed was then filtered, suspended in chloroform and used to fill glass Petri dishes. Finally, chloroform was evaporated allowing polymer recovery in the form of a thin film.

\section{Analytical procedures \\ OFMSW, digestate and percolates characterization}

Total solids (TS), volatile solids (VS), total nitrogen (TKN), $\mathrm{pH}$ and ammonia $\left(\mathrm{N}-\mathrm{NH}_{4}{ }^{+}\right.$) (detected on fresh material) contents were determined according to the standard procedures [26]. Total OA expressed as acetic acid, were detected on fresh material and determined according to the acid titration method [27].

\section{Substrate and biomass characterization during PHA production}

The substrates (OFMSW-supernatants) fed during the selection and accumulation processes were characterized in terms of $\mathrm{pH}$, TS, VS, Chemical Oxygen Demand (COD), OA content (acetate, butyrate, lactate, propionate and valerate), TKN, $\mathrm{N}_{-} \mathrm{NH}_{4}{ }^{+}$and phosphorus (P) content.

During the selection trials, samples were taken during the cycle once in each SRT; every sample was characterized in terms of total suspended solids (TSS), volatile suspended solids (VSS), soluble COD, OA content, $\mathrm{N}^{-\mathrm{NH}_{4}}{ }^{+}$ content and PHA content. During accumulation trials, samples were taken continuously in order to measure TSS, VSS, soluble COD, OA content and PHA content. Biomass concentration was calculated as VSS according to the standard methods [10].

TSS and VSS were determined as reported by Valentino et al. in 2015 [28]. OA concentrations measured on filtered samples (filter diameter of $0.45 \mu \mathrm{m}$ ) were determined by high-performance liquid chromatography (HPLC) using a chromatograph equipped with a UV detector and Aminex HPX-87H column (column temperature $20{ }^{\circ} \mathrm{C}, 0.0025 \mathrm{M} \mathrm{H}_{2} \mathrm{SO}_{4}$ eluent, flow rate $0.6 \mathrm{~mL} \mathrm{~min}^{-1}$ ). The OA concentrations were calculated through a standard calibration curve $\left(20-1000 \mathrm{mg} \mathrm{L}^{-1}\right.$ of each organic acid). The COD and the $\mathrm{N}^{-} \mathrm{NH}_{4}{ }^{+}$content (filtered at $0.45 \mu \mathrm{m}$ ) were determined using cuvette test kits (Macherey-Nagel, Germany).

PHAs were determined by GC MS using a method adapted from Serafim et al. in 2004 [22]. Lyophilized biomass was incubated for methanolysis in a $20 \% \mathrm{v} / \mathrm{v} \mathrm{H}_{2} \mathrm{SO}_{4}$ in $\mathrm{MeOH}$ solution $(1 \mathrm{~mL})$ and extracted with chloroform $(1 \mathrm{~mL})$. The mixture was digested at $100^{\circ} \mathrm{C}$ for $3.5 \mathrm{~h}$. After the digestion step, the organic phase (methylated monomers dissolved in chloroform) was extracted and injected $(1 \mathrm{~mL})$ into a gas chromatograph equipped with a detector (7980, Agilent Technologies, USA) and a ZB-Wax column $(30 \mathrm{~m}, 0.25 \mathrm{~mm}$ internal diameter, $0.25 \mu \mathrm{m}$ film thickness, Zebron, Phenomenex, USA), using helium as a carrier gas at $1.0 \mathrm{~mL} \mathrm{~min}^{-1}$. Samples were analysed under a temperature regime starting at $40{ }^{\circ} \mathrm{C}$, increasing to $100{ }^{\circ} \mathrm{C}$ at a rate of $20^{\circ} \mathrm{C} \mathrm{min}^{-1}$, to $175^{\circ} \mathrm{C}$ at a rate of $38^{\circ} \mathrm{C}$ $\mathrm{min}^{-1}$ and reaching a final temperature of $220^{\circ} \mathrm{C}$ at a rate of $20{ }^{\circ} \mathrm{C} \mathrm{min}{ }^{-1}$ for ensuring cleaning of the column after each injection. Injector and detector temperatures were at 280 and $230{ }^{\circ} \mathrm{C}$, respectively. Hydroxybutyrate (HB) and hydroxyvalerate $(\mathrm{HV})$ concentrations were determined through the use of two calibration curves, one for $\mathrm{HB}$ and another for $\mathrm{HV}$, using standards $\left(0.1-8 \mathrm{~g} \mathrm{~L}^{-1}\right)$ of a commercial P (HB-HV) (88/12\%) (Sigma-Aldrich, Germany), and corrected using heptadecane as internal standard (concentration of approximately $1 \mathrm{~g} \mathrm{~L}^{-1}$ ) (Sigma Aldrich, Germany).

\section{PHA and active biomass growth yield calculation}

The PHA content in cells was referred to VSS on a mass basis $\left[\mathrm{PHA}=\left(\mathrm{g} \mathrm{kg}^{-1} \mathrm{VSS}\right)\right]$, considering VSS to be constituted by both active biomass (X) and PHA [10]. PHA was converted into $\mathrm{COD}$ according to the following oxidation stoichiometry: $1.67 \mathrm{mg}$ COD mg $\mathrm{m}^{-1} \mathrm{HB}$ monomer and $1.92 \mathrm{mg} \mathrm{COD} \mathrm{mg}^{-1} \mathrm{HV}$ monomer [23].

Acetate, butyrate and lactate were considered as $\mathrm{HB}$ precursors, valerate and propionate as $\mathrm{HV}$ precursors [10]. X was calculated on a COD basis considering that $1 \mathrm{~g}$ of X contains $1.42 \mathrm{~g}$ of COD [23]. For the SBR, PHA storage yield was expressed in COD and referred to both COD consumed $\left(\mathrm{COD}_{\text {cons. }}\right)$ and $\mathrm{OA}$ consumed $\left(\mathrm{COD}_{\text {OA-cons. }}\right)$, calculated, respectively, as the ratio between the amount of PHA accumulated during the feast phase $\left(\mathrm{COD}_{\mathrm{PHA}}\right)$ and the amount of COD depleted or OA depleted. 
In the accumulation batches, these PHA storage yields were calculated as described before, for each pulse. In order to compare different accumulation tests, the average values of the first three pulses and for each parameter were considered [23].

In accumulation batches, PHA storage yield was also related to $\mathrm{COD}$ fed $\left(\mathrm{COD}_{\mathrm{in}}\right)$ and $\mathrm{OA}$ fed $\left(\mathrm{COD}_{\mathrm{OAin}}\right)$; moreover, it was also related back to total solids of OFMSW (OFMSW $\left.{ }_{\text {TS }}\right)$ and to OFMSW w.w. $_{\text {. }}$.

The $\mathrm{X}$ growth yield in the SBR was expressed in COD and referred to $\mathrm{COD}$ consumed $\left(\mathrm{COD}_{\text {cons. }}\right)$, calculated as the ratio between the new $\mathrm{X}$ produced during the feast phase $\left(\mathrm{COD}_{\mathrm{X}}\right)$ and the amount of COD depleted [23].

\section{PHA characterization by solid-state NMR and solution ${ }^{1} \mathrm{H}$ NMR, and molecular weight}

Solid-state ${ }^{13} \mathrm{C}$ NMR spectra of lyophilized biomass containing PHA were recorded on a Bruker Avance 300 spectrometer operating at $75.47 \mathrm{MHz}$, using a $4 \times 21 \mathrm{~mm}$ cylindrical zirconium rotor spun at $11,000 \mathrm{~Hz}$ to avoid the side bands. The ${ }^{13} \mathrm{C}$ cross-polarization magic angle spinning (CPMAS) NMR spectra were acquired using recycle delay of $8 \mathrm{~s},{ }^{1} \mathrm{H} 90$ pulse length of $3.5 \mu \mathrm{s}, 1 \mathrm{~m}$ contact time, acquisition time of $35 \mathrm{~ms}$ and from $1 \mathrm{~K}$ to $4 \mathrm{~K}$ scans. The ${ }^{13} \mathrm{C}$ single-pulse excitation (SPE) NMR spectra were recorded with delays of $160 \mathrm{~s}$ and $1-2 \mathrm{~K}$ scans.

The chemical shifts were recorded relative to tetramethylsilane via benzene as a secondary reference.

Liquid NMR experiments on extracted PHA were performed on a Bruker $500 \mathrm{MHz}$ AVANCE III NMR spectrometer (Bruker GmbH, Germany) with a $5-\mathrm{mm}$ TCI cryoprobe. Deuterated chloroform (99.96\%, Sigma Aldrich) was used as solvent. ${ }^{1} \mathrm{H}$ NMR spectra were recorded at $303 \mathrm{~K}$ using recycle delay of $12 \mathrm{~s}, 64 \mathrm{~K}$ fid size and 64 scans.

PHA molecular weight was determined by HP-SEC/ TDA measurement. The HPLC equipment consisted of a Viscotek system (Malvern Instrument Ltd, Malvern, UK) equipped with a Knauer HPLC pump K501, and a Biotech Degasi GPC degassing device. The detector system was a Viscotek mod. 302 Triple Detector Array (TDA), which is composed by Laser Light Scattering detector $\left(90^{\circ}\right.$ and $7^{\circ}$; wavelength $670 \mathrm{~nm}$ ), Refractive index (RI) detector [cell volume of $12 \mu \mathrm{L}$; light-emitting diode (LED) at $660 \mathrm{~nm}$ wavelength] and Viscosimeter detector (four capillaries with a differential Wheatstone bridge configuration). A PL GEL 20-um MIXED A column $(7.5 \times 300 \mathrm{~mm})$ was used. Chloroform was used as the mobile phase at a flow rate of $1 \mathrm{~mL} \mathrm{~min}{ }^{-1}$. Columns, injector and detectors were maintained at $30{ }^{\circ} \mathrm{C}$. Samples were dissolved in chloroform at concentrations of $2-8 \mathrm{mg} \mathrm{mL}^{-1}$ and filtered on a $0.2-\mu \mathrm{m}$ membrane before injection. Injection volume was of $100 \mu \mathrm{L}$.
The system was calibrated with the PS narrow standard of known $\mathrm{Mw}$, polydispersity and intrinsic viscosity (Malvern PolyCAL PS std $105 \mathrm{k}$ ). Using a standard PHA sample at different concentrations $(2.3,4.3,6.0$, $8.5 \mathrm{mg} \mathrm{mL}^{-1}$ ), the differential refractive index increment ( $\mathrm{dn} / \mathrm{dc}$ ) value was found to be equal to 0.024 and used for further calculations.

\section{Statistical analysis}

Average and standard deviation values were calculated according to standard procedures and the results were analysed by an ANOVA test. A Tukey's test was used to compare mean values and to assess the significance of the differences between mean values, adopting a fixed effects model, i.e. the digestate flow adopted modified the chemical composition of both the percolates produced and the supernatants derived.

All statistical analyses were carried out using the SPSS statistical software, version 15.0 (SPSS, Chicago, IL, USA).

\section{Results \\ Percolation trials}

Percolation trials carried out by adopting different irrigation regimes, i.e. varying digestate flow rate, showed differences in terms of total percolate produced, i.e. an increase of the hourly digestate flow rate determined an increase of the total percolate produced (Table 1). Again, the production of total OA increased by more than $200 \%$ when digestate flow rate doubled, when comparing Trial 1 with Trial 2 (Table 1). However, the further increase of digestate flow rate (Trial 3) did not lead to any increase of OA production and on the contrary, slightly decreased it.

Percolates obtained were similar in terms of chemical characteristics apart from the percolate coming from the third trial that appeared more diluted as regarded OA and $\mathrm{N}-\mathrm{NH}_{4}{ }^{+}$content (Table 1).

Trial 2 optimized OFMSW hydrolysis and subsequent acidogenesis fermentation, producing the highest amount of OA.

\section{OFMSW-supernatants}

Pre-treated percolates used for MMC production (OFMSW-supernatants in $_{\text {in }}$ ) showed no statistical differences in terms of COD and $\mathrm{N}-\mathrm{NH}_{4}{ }^{+}$contents, apart from the $\mathrm{P}$ content and $\mathrm{HB} / \mathrm{HV}$ precursors ratio which were higher for OFMSW-supernatant ${ }_{\text {in }} 3$ than for the other OFMSW-supernatants in $_{\text {(Table 2). }}$.

OFMSW-supernatants used to perform PHA accumulation tests (OFMSW-supernatants acc. $_{\text {) }}$ ) were again quite similar to each other, with the exception for P content and $\mathrm{HB} / \mathrm{HV}$ precursors ratio which were higher for 
Table 1 Percolation trials conditions (a) and composition of OFMSWs and digestates used and of percolates produced (b)

\begin{tabular}{|c|c|c|c|c|c|c|}
\hline Trial & $\mathrm{T}\left({ }^{\circ} \mathrm{C}\right)$ & Duration (day) & OFMSW (kg) & $\begin{array}{l}\text { Digestate flow rate } \\
\left(\mathrm{L} \mathrm{h}^{-1} \mathbf{k g}^{-1} \text { OFMSW }_{\text {w.w. }}\right)\end{array}$ & $\begin{array}{l}\text { Percolate produced } \\
\left(\mathrm{L} \mathrm{kg}^{-1} \text { OFMSW }_{\text {w.w. }}\right)\end{array}$ & $\begin{array}{l}\text { OA produced } \\
\left(\text { kg }^{-1} \text { OFMSW }_{\text {w.w. }}\right)\end{array}$ \\
\hline \multicolumn{7}{|l|}{$a$} \\
\hline Trial 1 & 30 & 21 & 44 & 0.02 & 8.03 & 60.5 \\
\hline Trial 2 & 30 & 21 & 42.7 & 0.04 & 19.3 & 151 \\
\hline Trial 3 & $\begin{array}{l}40 \text { (day } 1-8) \\
30 \text { (day 9-21) }\end{array}$ & 21 & 43.6 & $\begin{array}{l}0.08 \text { (1-8 day) } \\
0.04 \text { (9-21 day) }\end{array}$ & 25.57 & 139 \\
\hline Trial & & TS (\%) & VS (\%) & $\mathrm{pH}$ & $O A^{a}\left(\mathrm{mg} \mathrm{L}^{-1}\right)$ & $\mathrm{N}-\mathrm{NH}_{4}{ }^{+}\left(\mathrm{mg} \mathrm{L}^{-1}\right)$ \\
\hline \multicolumn{7}{|l|}{ b } \\
\hline \multicolumn{7}{|c|}{ Trial 1, 2, 3} \\
\hline OFM & W (average) & $24.5 \pm 3.9$ & $86.8 \pm 2.6$ & $4.3 \pm 0$ & $11,663 \pm 1.649$ & $304 \pm 239$ \\
\hline \multicolumn{7}{|c|}{ Trial $1,2,3$} \\
\hline Dige & tate (average) & $2.2 \pm 0.2$ & $70.8 \pm 2.7$ & $8.32 \pm 0.1$ & $3448 \pm 1.591$ & $2065 \pm 343$ \\
\hline \multicolumn{7}{|c|}{ Trial 1} \\
\hline Perc & ate 1 (P1) & $2.4 \pm 0.49 a^{b}$ & $71.2 \pm 2.2 \mathrm{~b}$ & $6.91 \pm 0.19 a$ & $7540 \pm 1,474 b$ & $2231 \pm 130 b$ \\
\hline \multicolumn{7}{|l|}{ Trial 2} \\
\hline Perc & ate 2 (P2) & $1.9 \pm 1.1 \mathrm{a}$ & $66.5 \pm 2.8 \mathrm{a}$ & $6.99 \pm 0.61 a$ & $7831 \pm 1,775 b$ & $2412 \pm 472 b$ \\
\hline \multicolumn{7}{|c|}{ Trial 3} \\
\hline Perc & ate 3 (P3) & $2 \pm 0 a$ & $73 \pm 2 \mathrm{a}$ & $6.99 \pm 0.32 a$ & $5437 \pm 818 \mathrm{a}$ & $1784 \pm 117 a$ \\
\hline
\end{tabular}

a OA expressed as acetic acid, determined according to the acid titration method [27]

b Limited to percolates, values in the same column followed by the same letter are not statistically different (ANOVA, Tukey test, $p<0.05)$

Table 2 Chemical composition of the substrates used in the MMC selection and PHA accumulation processes

\begin{tabular}{|c|c|c|c|c|c|c|c|}
\hline Substrate & $\operatorname{COD}\left(\mathrm{mg} \mathrm{L}^{-1}\right)$ & $\mathrm{N}-\mathrm{NH}_{4}{ }^{+}\left(\mathrm{mg} \mathrm{L}^{-1}\right)$ & $P$ tot $\left(\mathrm{mg} \mathrm{L}^{-1}\right)$ & $\mathrm{C}\left(\mathrm{mmol} \mathrm{L}^{-1}\right)$ & $\begin{array}{l}\mathrm{N}-\mathrm{NH}_{4}^{+} \\
\left(\mathrm{mmol} \mathrm{L}^{-1}\right)\end{array}$ & $\mathrm{P}\left(\mathrm{mmol} \mathrm{L}^{-1}\right)$ & $\begin{array}{l}\text { Organic acids com- } \\
\text { position (\%, weight } \\
\text { basis, HB precur- } \\
\text { sors/HV precursors) }\end{array}$ \\
\hline $\begin{array}{l}\text { OFMSW-superna- } \\
\operatorname{tant}_{\text {in }} 1\end{array}$ & $1304 \pm 10 a^{a}$ & $46.7 \pm 4.9 a$ & $3.1 \pm 0.3 a$ & $34.4 \pm 0.3 a$ & $2.6 \pm 0.3 a$ & $0.1 \pm 0 a$ & $59.7 / 40.3$ \\
\hline $\begin{array}{l}\text { OFMSW-superna- } \\
\operatorname{tant}_{\text {in }} 2\end{array}$ & $1322 \pm 37^{\circ}$ & $56.2 \pm 7.5 a$ & $3.6 \pm 0.4 a$ & $34.9 \pm 1 a$ & $3.1 \pm 0.4 a$ & $0.12 \pm 0.01 a$ & $51.2 / 48.8$ \\
\hline $\begin{array}{l}\text { OFMSW-superna- } \\
\operatorname{tant}_{\text {in }} 3\end{array}$ & $1231 \pm 63 a$ & $58.4 \pm 8.1 \mathrm{a}$ & $5.6 \pm 0.6 b$ & $32.5 \pm 1.7 a$ & $3.2 \pm 0.5 \mathrm{a}$ & $0.18 \pm 0.02 b$ & $67.8 / 32.2$ \\
\hline $\begin{array}{l}\text { OFMSW-superna- } \\
\operatorname{tant}_{\text {acc. }} 1\end{array}$ & $7591 \pm 54 a$ & $28 \pm 4 a$ & $16.9 \pm 2.3 a$ & $200 \pm 2 a$ & $1.6 \pm 0.2 \mathrm{a}$ & $0.55 \pm 0.07 a$ & $57.2 / 42.8$ \\
\hline $\begin{array}{l}\text { OFMSW-superna- } \\
\text { tant }_{\text {acc. }} 2\end{array}$ & $7879 \pm 87 a$ & $29.1 \pm 2 a$ & $19.8 \pm 3 a$ & $207.8 \pm 2.3 a$ & $1.6 \pm 0.1 \mathrm{a}$ & $0.64 \pm 0.11 \mathrm{a}$ & $52 / 48$ \\
\hline $\begin{array}{l}\text { OFMSW-superna- } \\
\text { tant }_{\text {acc. }} 3\end{array}$ & $7253 \pm 98 a$ & $26.8 \pm 3 a$ & $31.1 \pm 5.2 b$ & $191.3 \pm 2.6 a$ & $1.5 \pm 0.2 \mathrm{a}$ & $1 \pm 0 b$ & $65.1 / 34.9$ \\
\hline
\end{tabular}

a By separating OFMSW-supernatants ${ }_{\text {in }}$ from OFMSW-supernatants acc, $_{\text {, }}$ values in the same column followed by the same letter are not statistically different (ANOVA, Tukey test, $p<0.05)$

OFMSW-supernatant $\mathrm{acc}_{\text {ac. }} 3$ than for the other OFMSWsupernatants $_{\text {acc. }}$ (Table 2).

\section{Mixed microbial culture enrichment}

The amount of PHA stored at the end of the feast phase and PHA storage yields, measured for the mixed microbial culture during the selection process, remained quite stable (Table 3) during the first 2 months of selection when
OFMSW-supernatants in $_{1} 1$ and 2 were used as substrates. In particular, PHA stored at the end of the feast phase was subject to small fluctuations with an average value of $363 \pm 30 \mathrm{~g} \mathrm{~kg}^{-1}$ VSS. PHA storage yields (expressed as $\mathrm{COD}$ ) on COD and on OA consumed were, on average, of $0.52 \pm 0.07 \mathrm{mg} \mathrm{mg}^{-1} \mathrm{COD}_{\text {cons}}$, and of $0.86 \pm 0.23 \mathrm{mg} \mathrm{mg}^{-1}$ $\mathrm{COD}_{\mathrm{OA}-\mathrm{cons}}$, respectively, indicating the main role of $\mathrm{OA}$ among different carbon sources in PHA production $[7,11]$. 


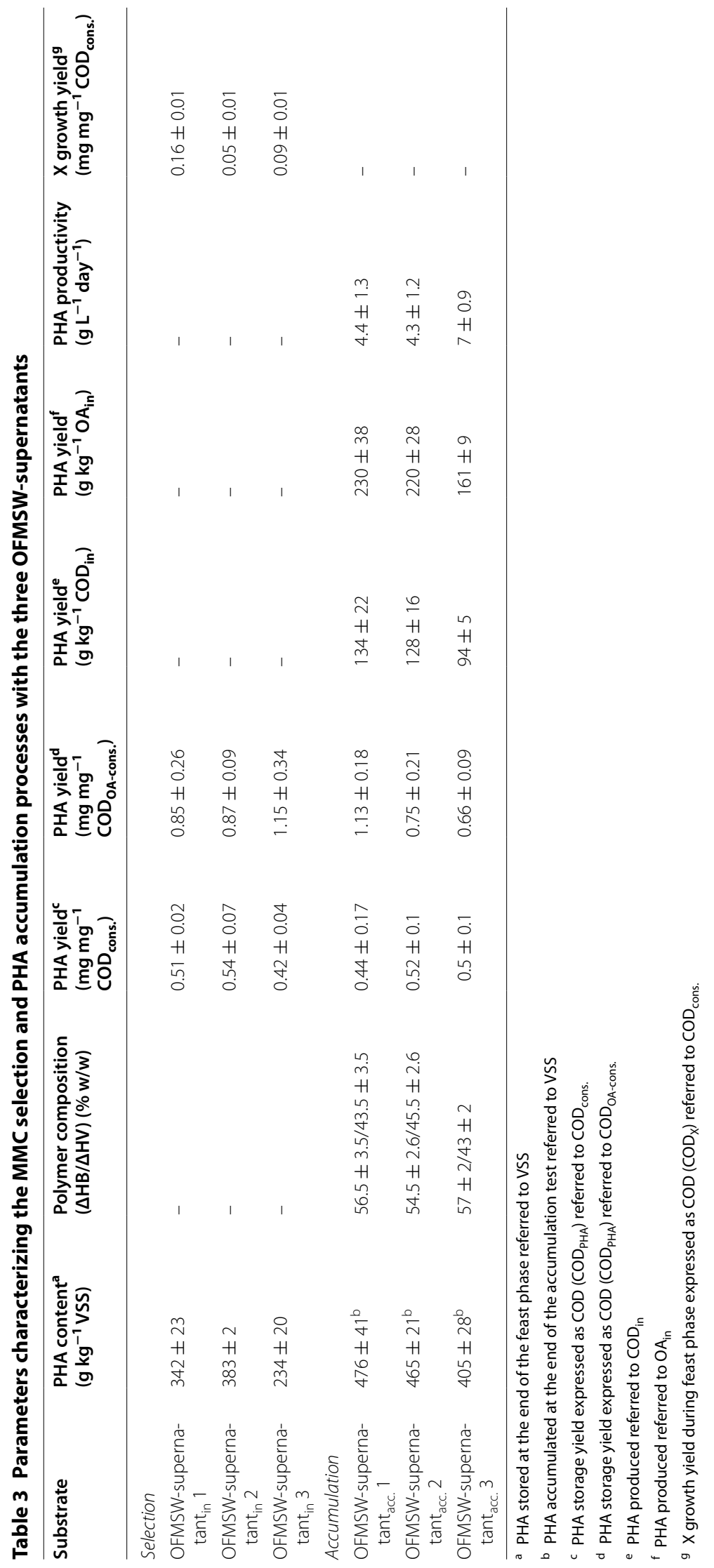


The culture fed with OFMSW-supernatant in 3 gave different results as the polymer content at the end of the feast phase and PHA storage yield on COD consumed were lower by 36 and $20 \%$ in comparison with the data reported for OFMSW-supernatants $\mathrm{s}_{\text {in }} 1$ and 2 . On the other hand, PHA storage yield on OA consumed increased by $34 \%$. In any case, performance obtained with OFMSW-supernatant $_{\text {in }} 3$ was better than that reported in the literature for similar substrates (OFMSW leachate) $[17,18]$ and it was comparable to those obtained with other waste substrates (e.g. fermented molasses and fermented cheese whey) [10, 29]. Probably, differences found in terms of reduction of polymer content were because OFMSW-supernatant $_{\text {in }} 3$ was characterized by a higher presence of $\mathrm{P}$ that reduced PHA accumulation [30].

Feast-to-famine ratio obtained during all selection processes using the three OFMSW-supernatants ${ }_{\text {in }}(\mathrm{F} / \mathrm{F}$ ratio ranged from 0.03 to 0.15 ) (Fig. 2), confirmed the good performance of the selection procedures, indicating successful enrichment in PHA-accumulating bacteria [23].

\section{PHA production}

Accumulation tests (Table 3) revealed a better performance for the cultures selected with OFMSWsupernatants $_{\text {in }} 1$ and 2 than that of 3 in terms of PHA accumulation in relation to VSS. Maximum PHA content at the end of the tests fed with OFMSW-supernatants acc. $_{\text {. }}$
1 and 2 was of $467 \pm 41 \mathrm{~g} \mathrm{~kg}^{-1}$ VSS and $465 \pm 21 \mathrm{~g} \mathrm{~kg}^{-1}$ VSS, respectively, which were about $13 \%$ higher than that obtained in the tests fed with OFMSW-supernatant $\mathrm{acc}_{\text {ace }}$ 3 (Table 3). These results were similar to those obtained in previous work using other waste substrates (e.g. palm oil mill effluent, fermented olive oil mill pomace, crude glycerol) [31-33], indicating a reliable performance of the cultures in accumulation tests. In terms of PHA storage yields (expressed as COD) on COD consumed, PHA accumulation carried out by using the three supernatants gave substantially similar results when OFMSW-supernatants $_{\text {acc. }} 2$ and 3 were used, i.e. $0.5 \mathrm{mg} \mathrm{mg}^{-1} \mathrm{COD}_{\text {cons. }}$. These data were higher than those detected for the accumulation trial using OFMSW-supernatant $\mathrm{acc}_{\text {. }} 1$.

PHA storage yields (expressed as COD) referred to as consumed-OA were very different for different supernatants. For example, PHA yield was reduced from 1.13 to $0.66 \mathrm{mg} \mathrm{mg}^{-1} \mathrm{COD}_{\mathrm{OA} \text {-cons. }}$ when comparing the trial performed using the OFMSW-supernatant $\mathrm{acc}_{\text {ac. }} 1$ to the one using the OFMSW-supernatant ${ }_{\text {acc. }}$ 3. Residual OA could be potentially reused to produce PHA or destined to the production of biogas and energy, supporting the entire process throughout anaerobic digestion. These solutions have not been considered in this work.

Trials performed using the OFMSW-supernatant$\mathrm{s}_{\text {acc. }} 1$ and 2 , gave the highest PHA production with respect to the total $\mathrm{COD}$ and $\mathrm{OA}$ fed, i.e., as average, $130 \pm 16 \mathrm{~g} \mathrm{~kg}^{-1} \mathrm{COD}_{\mathrm{in}}$ and $223 \pm 28 \mathrm{~g} \mathrm{~kg}^{-1} \mathrm{OA}_{\mathrm{in}}$, that

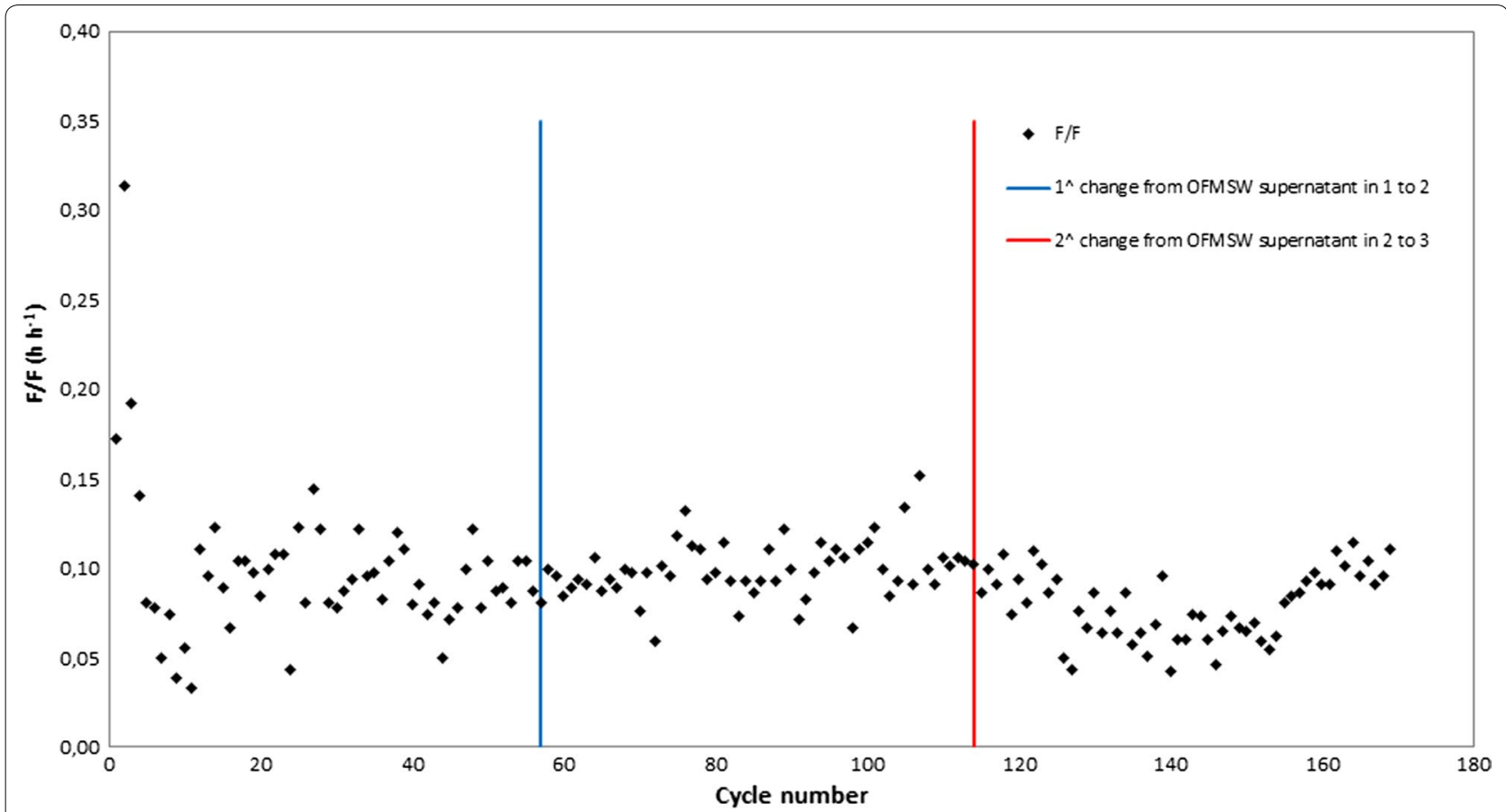

Fig. 2 Feast-to-famine ratio (F/F) during the entire selection process with the three OFMSW-supernatants in 
were $30 \%$ higher than data obtained for the culture fed with the OFMSW-supernatant ${ }_{\text {acc. }}$ 3. Lower PHA production was probably due to the decrease of biomass which occurred in the SBR during the last month (data not reported).

PHA composition was constant among the three different accumulation tests performed, with an average value of $56 \pm 3 \%$ of $\mathrm{HB}$ and $44 \pm 3 \%$ of $\mathrm{HV}$, as detected by the GC-MS approach. This composition was similar to that obtained by Amulya et al. in 2015 [17] using fermented OFMSW as substrate.

\section{Discussion}

\section{PHA production and mass balance}

Results above discussed indicated that supernatants obtained worked well as substrates to select and enrich MMC in PHA-storing bacteria. In particular, PHA content at the end of the feast phase and PHA yield on COD and on OA consumed obtained in this work were comparable or higher than those reported in the literature for selection processes of mixed microbial cultures obtained by feeding similar OFMSW leachate $[17,18]$ or other waste substrates (e.g. fermented molasses and fermented cheese whey) [10,29]. Best performances obtained could be due to the fact that in this work culture enrichment was performed at $30^{\circ} \mathrm{C}$, which is an optimal temperature for microbial activity, and because a more balanced C:N ratio (close to 10) was adopted with respect to the lower values adopted by other authors $[15,18]$.

The good results above discussed allowed us to get PHA contents during PHA accumulation tests higher than those reported in the literature by Amulya et al. in 2015 [17] and comparable to the data reported by Zhang et al. in 2014 [16], both working on food wastes (Table 4). On the other hand, PHA contents were clearly lower than those obtained by Korkakaki et al. in 2016 [18], who obtained PHA contents of 778-784 $\mathrm{g} \mathrm{kg}^{-1}$ VSS (Table 4) by feeding fermented food wastes to a MMC, achieving very similar results to those reported for pure cultures (860-870 $\mathrm{g} \mathrm{kg}^{-1}$ VSS by using Cupriavidus necator) $[34,35]$ (Table 4). Nevertheless, it should be specified that those data were obtained by using a mix of synthetic volatile fatty acids (VFAs) $(75-90 \% \mathrm{w} / \mathrm{w})$ and OFMSW leachate $(10-25 \% \mathrm{w} / \mathrm{w})$ during the selection procedure. Korkakai et al. in 2016 reported that the use of pure leachate as the sole substrate to select PHA-accumulating bacteria was less successful than the use of a feed made mainly by synthetic VFAs, because the microbial culture selected with VFAs maintained a high PHA storage capacity even if fed with pure leachate.

The PHA yields obtained, i.e. $0.44-0.52 \mathrm{mg} \mathrm{mg}^{-1}$ $\mathrm{COD}_{\text {cons. }}$ and $0.65-1.13 \mathrm{mg} \mathrm{mg}^{-1} \mathrm{COD}_{\mathrm{OA} \text {-cons. }}$ (Table 4), were very good and comparable to those reported in the literature by using other waste substrates to produce PHA (e.g. fermented olive oil mill effluent, fermented molasses, fermented cheese whey) [10-12]. Moreover, results from this work were higher than that reported by Zhang et al. in 2014 [16] concerning the use of fermented food waste and sewage sludge as the substrate for PHA production (Table 4).

Table 5 reports the mass balance of the entire process: the percolation process producing OA (first stage) plus PHA accumulation (second stage).

Percolation trials indicated that the process parameters adopted for Trial 2 determined the highest percolate and OA production per $\mathrm{kg}$ of OFMSW treated, giving the best trial results among the three tested. This evidence together with the very good performance in converting OA into PHA (second stage) using the OFMSW-supernatant $_{\text {acc. }}$ 2, resulted in the highest PHA production among the three two-stage processes, i.e. $33.22 \pm 4.2 \mathrm{~g} \mathrm{~kg}^{-1}$ of OFMSW $_{\text {w.w. }}$, corresponding to $114.4 \pm 14.5 \mathrm{~g} \mathrm{~kg}^{-1}$ of OFMSW $_{\mathrm{TS}}$, almost 5 times higher than that reported by Rhu et al. in 2003 [15] (25 g of PHA kg-1 of dry food waste).

\section{PHA characterization}

Mass balance previously discussed indicated that Trial 2 gave the best results in terms of total PHA yield. Therefore, PHA characterization was focused on the products obtained in Trial 2.

Solid-state ${ }^{13} \mathrm{C}$ NMR was used to evaluate the content of PHA in the generated biomass and to monitor the PHA extraction process. ${ }^{13} \mathrm{C}$ cross polarization NMR technique, based on the carbon magnetization transferred from ${ }^{1} \mathrm{H}$ protons, could not be used for quantification of different chemical species/functional groups. In contrast, single-pulse excitation (SPE) NMR is based on the direct ${ }^{13} \mathrm{C}$ nuclei polarization and, even if less sensitive than CP MAS NMR, can be optimized for quantitative evaluation analysis. The most critical parameter, recycle delay, was set at $160 \mathrm{~s}$, in order to cover T1 values of each ${ }^{13} \mathrm{C}$ type [36]. The obtained ${ }^{13} \mathrm{C}$ SPE NMR of the reference PHA standard, biomass enriched in PHA and the biomass after PHA extraction are shown in Fig. 3.

Together with the PHA signals, the biomass spectrum contains signals compatible with proteins (large CO peak at $170-185 \mathrm{ppm}$ ), minor polysaccharides (large peak of anomeric $\mathrm{O}-\mathrm{C}-\mathrm{O}$ at $100-110 \mathrm{ppm})$, etc. It is worth noting that PHA-related peaks are sharper than the other signals, indicating that these polymers were present, at least partially, in their semi-crystalline form.

In spite of the optimized acquisition parameters, quantitative analysis of PHA in biomass was limited by strong signal overlapping, especially in the aliphatic region (0-80 ppm) (Fig. 3). As a tentative for PHA quantitative 


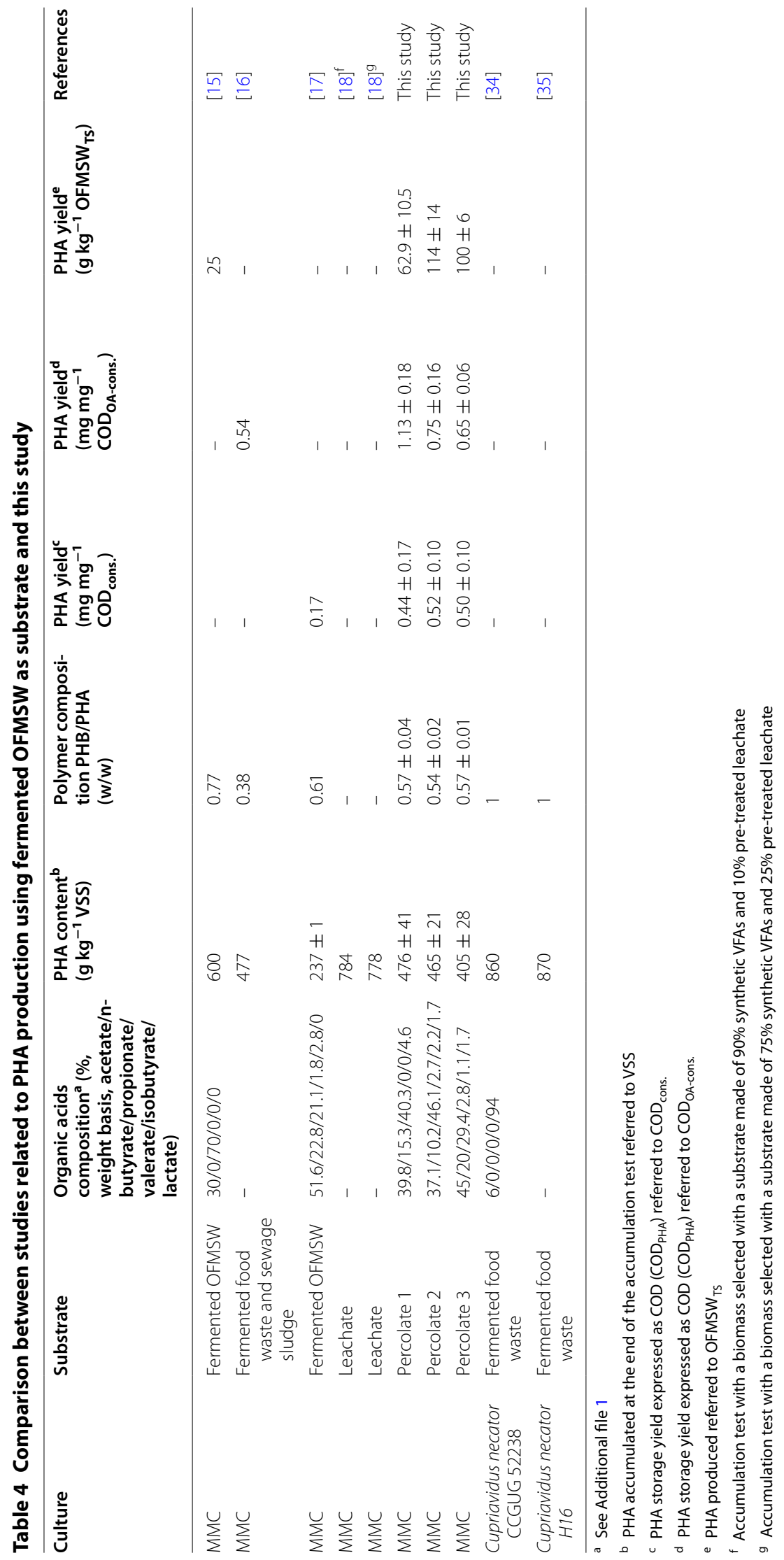


Table 5 PHA yield on OFMSW weight unit

\begin{tabular}{|c|c|c|c|c|c|}
\hline & \multicolumn{2}{|l|}{ First stage } & \multirow{2}{*}{$\begin{array}{l}\text { Second stage } \\
\text { PHA yield } \\
\left(\mathrm{g} \mathrm{kg}^{-1} \mathrm{OA}_{\mathrm{in}}\right)\end{array}$} & \multicolumn{2}{|l|}{ Global process } \\
\hline & $\begin{array}{l}\text { Percolate produced } \\
\left.{\text { ( } \text { kg }^{-1} \text { OFMSW }}_{\text {w.w. }}\right)\end{array}$ & $\begin{array}{l}\text { OA produced }^{\mathrm{a}} \\
\left.\text { (g kg }^{-1} \text { OFMSW }_{\text {w.w. }}\right)\end{array}$ & & $\begin{array}{l}\text { PHA yieldc } \\
\left(\mathrm{g} \mathrm{kg}^{-1} \text { OFMSW }_{\text {TS }}\right)\end{array}$ & $\begin{array}{l}\text { PHA yield } \\
\left(g^{d} g^{-1} \text { OFMSW }_{\text {w.w. }}\right)\end{array}$ \\
\hline Trial 1 & 8.03 & 60.5 & $230 \pm 38$ & $62.9 \pm 10.5$ & $13.9 \pm 2.3$ \\
\hline Trial 2 & 19.3 & 151 & $220 \pm 28$ & $114 \pm 14$ & $33.2 \pm 4.2$ \\
\hline Trial 3 & 25.6 & 139 & $161 \pm 9$ & $100 \pm 6$ & $22.4 \pm 1.3$ \\
\hline
\end{tabular}

a OA expressed as acetic acid, determined according to the acid titration method [27]

b PHA produced referred to $O A_{\text {in }}$

c PHA produced referred to OFMSW

d PHA produced referred to OFMSW w.w

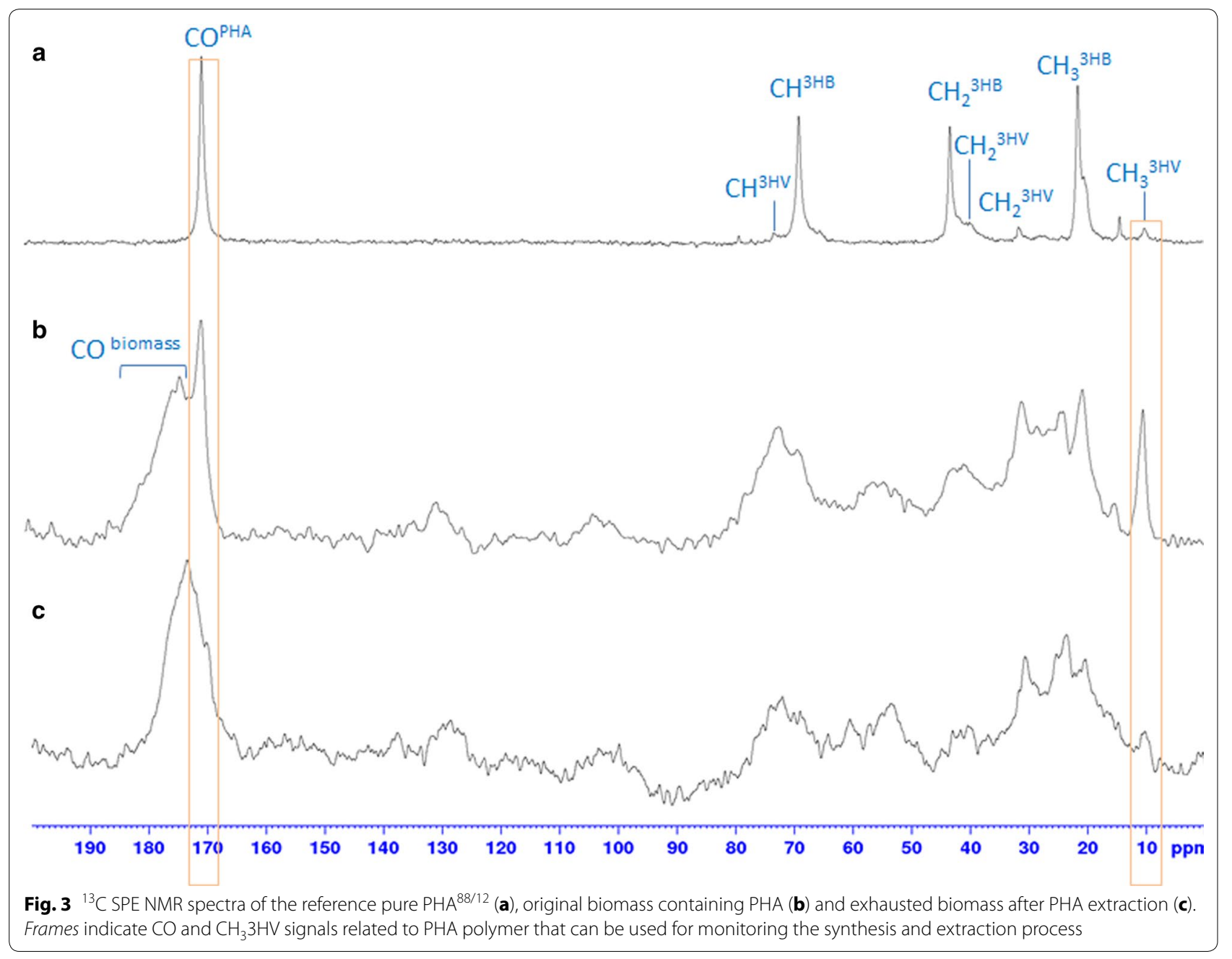

evaluation in the original biomass, a ratio between $\mathrm{CO}^{\mathrm{PHA}}$ and $\mathrm{CO}^{\text {biomass }}$ was estimated as $30-35$ molar \%, using a Topspin software for peak integral simulation. Since the result significantly depends on the estimated signal width, such an approach could not be applied for the exhausted biomass, where the $\mathrm{CO}^{\mathrm{PHA}}$ peak is not sufficiently high. It still can be clearly observed from the decreased signals of $\mathrm{CO}^{\mathrm{PHA}}(\sim 172 \mathrm{ppm})$ (Fig. 3) and well isolated $\mathrm{CH}_{3}^{3 \mathrm{HV}}(\sim 10 \mathrm{ppm})$ (Fig. 3) that the biomass treated with chloroform contained PHA in lower quantity. Notably, even before extraction, it can be seen that the synthesized PHA are characterized by higher content 
of $3 \mathrm{HV}$ monomer that is in agreement with GC-MS data. Altogether, these data can be useful for monitoring the PHA content in biomass during their production and extraction.

In order to provide more detailed structural features of the extracted PHA polymers, solution ${ }^{1} \mathrm{H}$ NMR, GCMS and GPC-TDA were applied along with solid-state NMR. By doing so, extracted PHA was characterized by ${ }^{1} \mathrm{H}$ NMR using standard $\mathrm{PHA}^{88 / 12}$ for signal assignment (Fig. 4).

The PHA-related signals assigned using ${ }^{1} \mathrm{H}$ and COSY NMR (not shown) were in agreement with the previously published data [37]. The molar $3 \mathrm{HB} / 3 \mathrm{HV}$ composition for commercial standard $\mathrm{PHA}^{88 / 12}$ and biosynthesized
PHA determined by ${ }^{1} \mathrm{H}$ NMR is reported in Table 6. Notably, quantitative data obtained for the biosynthesized PHA by ${ }^{1} \mathrm{H}$ NMR (53/47\%) (Table 6) are also in agreement with $\mathrm{GC}-\mathrm{MS}$ results.

Gel permeation chromatography with a TDA detection system was used to describe the molecular weight distribution of the biosynthesized PHA. Separation and detection conditions (including $d n / d c$ calculation) were optimized using a commercial PHA ${ }^{88 / 12}$ sample. Table 6 reports the average molecular weight $\mathrm{Mw}$, polydispersity and hydrodynamic radius $\mathrm{Rh}$ determined for the reference $\mathrm{PHA}^{88 / 12}$ and extracted PHA sample. In spite of a similar polydispersity, the biosynthesized PHA sample was characterized by higher molecular weight and

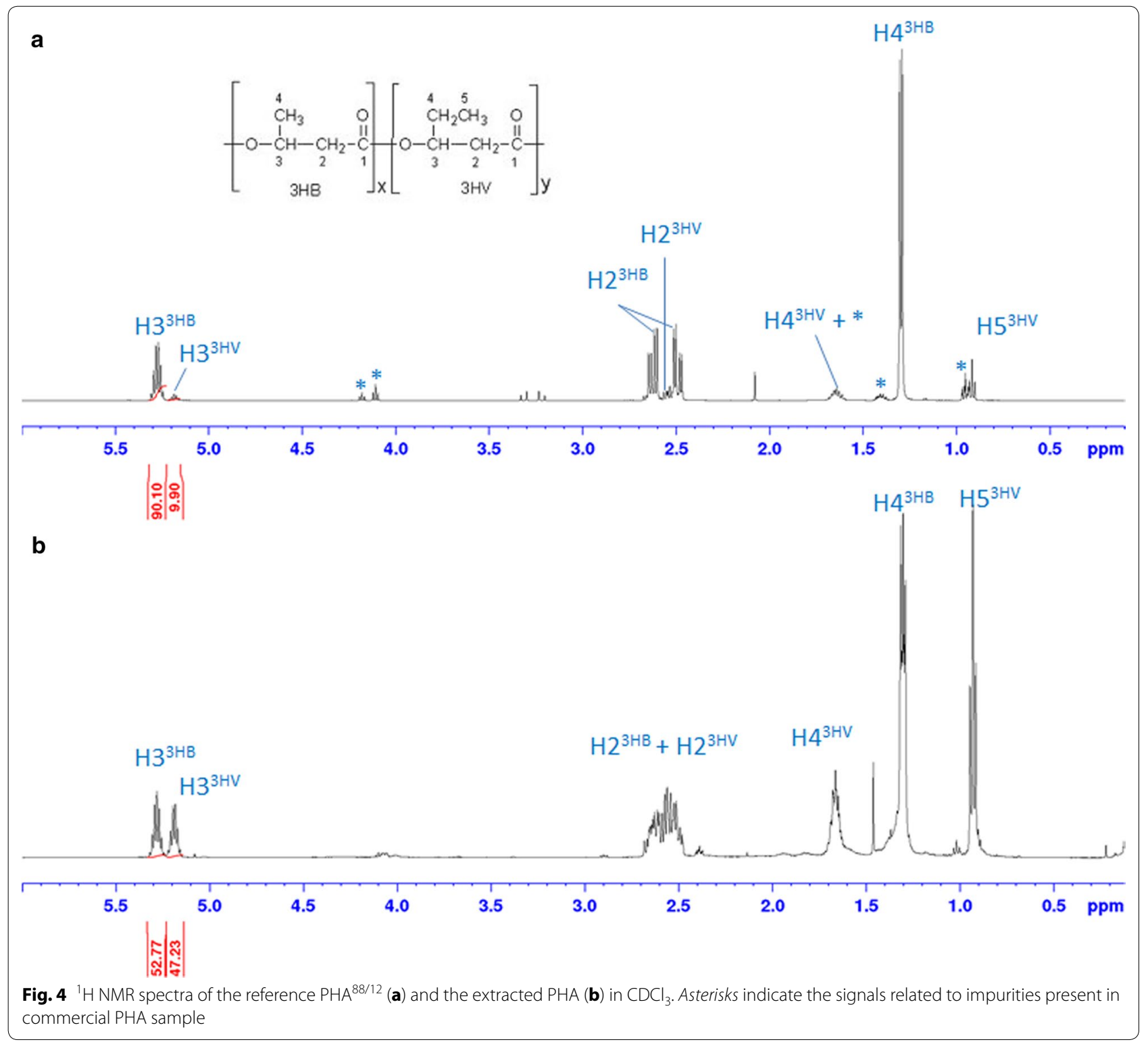


Table 6 Characterization of PHA produced in the accumulation stage of Trial 2 compared with commercial PHA ${ }^{88 / 12}$

\begin{tabular}{|c|c|c|c|c|c|c|}
\hline Products & $\mathrm{HB} / \mathrm{HV}^{\mathrm{a}}$ (molar ratio) & $M w^{\mathbf{b}}(\mathrm{kDa})$ & Polydispersity & $\mathrm{Rh}^{\mathrm{c}}(\mathrm{nm})$ & $a^{\mathrm{d}}$ & $\log K^{\mathrm{d}}$ \\
\hline Commercial reference-PHA ${ }^{88 / 12}$ & $90 / 10$ & $2 \cdot 10^{5}$ & 1.3 & 14 & 0.70 & -3.8 \\
\hline Extracted PHA from Trial 2 & $53 / 47$ & $8 \cdot 10^{5}$ & 1.4 & 29 & 0.65 & -3.4 \\
\hline
\end{tabular}

${ }^{a}$ Molar ratio such as detected by NMR

${ }^{b}$ Molecular weight distribution determined by GPC-TDA

c Hydrodynamic Radius determined by GPC-TDA

${ }^{d}$ Mark-Houwink parameters $a$ and $\log K$

hydrodynamic radius. Mark-Houwink parameters $a$ and $\log K$, reflecting conformational behaviour of polymers in solution, are also reported in Table 6. The obtained $a$ values for reference $\mathrm{PHA}^{88 / 12}$ and extracted PHA are compatible with the values characteristic for flexible polymers in solution. Interestingly, these properties do not depend on the differences in molecular weight and chemical composition between the two samples.

\section{Conclusions}

Data obtained in this work can be useful as the starting point for considering both technical and economic feasibility of PHA production from OFMSW by using MMC.

The optimization of OFMSW acidic fermentation resulted a key step for the success of PHA production because it allows the production of a large amount of OA to be used to produce PHA. Moreover, the high concentrations of OA acted to prevent biogas (methane) production from consuming the substrate to be used to produce PHA. This kind of process could be rapidly implemented in a full-scale plant by adapting dry anaerobic digestion that is commonly used to produce biogas from household wastes.

This work, for the first time, reported that PHA yield referred to an OFMSW weight unit in an optimized process. Therefore, taking into consideration a PHA value of 2600-5800 \$ tonne ${ }^{-1}$ [38], data of total food waste produced in EU (87.6 million tonnes) and PHA yield obtained in this work $\left(33.2 \mathrm{~g} \mathrm{~kg}^{-1} \mathrm{OFMSW}_{\text {w.w. }}\right)$, in theory a total gross revenue of 7.6-16.9 billion $\$$ might be achieved.

\section{Additional file}

Additional file 1. Specific acids composition of fermented OFMSW used as substrate for PHA production in literature and in this study. Table reporting the specific acids composition of fermented OFMSW used as substrate for PHA production in literature and in this study.

\section{Abbreviations}

OA: organic acids; OFMSW: organic fraction of municipal solid waste; PHA: polyhydroxyalkanoates; FW: food waste; MMC: mixed microbial cultures; APBR: anaerobic percolation biocell reactor; SBR: sequencing batch reactor; OFMSWsupernatant ${ }_{\text {in }}$ : substrate for PHA selection phase; OFMSW-supernatants acc: substrate for PHA accumulation phase; W.W.: wet weight; TS: total solids; VS: volatile solids; TSS: total suspended solids; VSS: volatile suspended solids; CODPHA: PHA expressed as COD; $C_{\text {in }}$ : $C O D$ fed; COD $_{\text {cons: }}$ : $C O D$ consumed; $\mathrm{OA}_{\text {in }}$ : organic acids fed; $\mathrm{COD}_{\mathrm{OA}-\mathrm{cons}}$ : organic acids consumed expressed as $\mathrm{COD} ; \mathrm{X}$ : active biomass; $\mathrm{COD}_{\mathrm{X}}$ : active biomass expressed as $\mathrm{COD} ; \mathrm{HB}$ : hydroxybutyrate; HV: hydroxyvalerate.

\section{Authors' contributions}

$\mathrm{BC}$ designed and performed the experiments from the treatment of the percolates of OFMSW to PHA production, collected data, analysed data and drafted the manuscript. FF helped in performing and collecting data from the treatment of the percolates of OFMSW to PHA production. BS performed GC-MS analysis for PHA determination. TPS helped in designing the experiments from the treatment of the percolates of OFMSW to PHA production. GD designed the experiments related to percolates of OFMSW production. MP performed the experiments related to percolates of OFMSW production, collected data and analysed data. CC and AA designed the solid-state NMR experiments, and processed and interpreted the obtained data. CC performed the acquisition of solution and solid-state NMR spectra. GE conducted the SEC-TDA experiments and analysed the obtained data as well as interpreted the ${ }^{1} \mathrm{H}$ NMR spectra. AA gathered all the experimental data and wrote the SECTDA/NMR portion of the manuscript. FA designed, conceived and supervised the entire work, drafted and revised the manuscript. All authors read and approved the final manuscript.

\section{Author details \\ ${ }^{1}$ Gruppo Ricicla labs-DiSAA-Università degli Studi di Milano, Via Celoria 2, 20133 Milan, Italy. ${ }^{2}$ Centro Alta Tecnologia Istituto di Ricerche Chimiche e Biochimiche G. Ronzoni Srl, Via Colombo 81, 20133 Milan, Italy. ${ }^{3}$ Istituto di Ricerche Chimiche e Biochimiche G. Ronzoni, Via Colombo 81, 20133 Milan, Italy.}

\section{Acknowledgements}

We acknowledge the support of Cap Holding (Peschiera Borromeo plant, Italy) who provided the sewage sludge necessary for carrying out MMC isolation for PHA production.

\section{Competing interests}

The authors declare that they have no competing interests.

\section{Consent for publication}

The authors agree to publish in the journal.

\section{Funding}

This work was financed by Regione Lombardia, Italian Governement and European Community-Programma Operativo Regionale 2014-2020, Obiettivo "Investimenti in Favore della Crescita e dell'Occupazione Asse Prioritario I Rafforzare la Ricerca, lo Sviluppo e I'Innovazione. Azione I.1.b.1.3-Sostegno alle attività collaborative di R\&S per lo sviluppo di nuove tecnologie sostenibili, di nuovi prodotti e Servizi. Project ID 141082: Renewable RAw materials valorisation for INnovative BiOplastic production from urban Waste (RAINBOW).

\section{Publisher's Note}

Springer Nature remains neutral with regard to jurisdictional claims in published maps and institutional affiliations. 
Received: 16 June 2017 Accepted: 12 August 2017 Published online: 22 August 2017

\section{References}

1. Pfaltzgraff $L A$, De Bruyn $M$, Cooper EC, Budarin V, Clark JH. Food waste biomass: a resource for high-value chemicals. Green Chem. 2013:15:307-14

2. Stenmarck $\AA$, Jensen C, Quested T, Moates G. Estimates of European food waste levels. Stockholm: Swedish Environmental Research Institute; 2016. http://www.eu-fusions.org/phocadownload/Publications/Estimates\%20 of\%20European\%20food\%20waste\%20levels.pdf.

3. Girotto F, Alibardi L, Cossu R. Food waste generation and industrial uses: a review. Waste Manage. 2015;45:32-41.

4. Kiran EU, Trcinski AP, Ng WJ, Liu Y. Enzyme production from food wastes using a biorefinery concept. Waste Biomass Valorization. 2014:5:903-17.

5. Kiran EU, Trcinski AP, Liu Y. Platform chemical production from food wastes using a biorefinery concept. J Chem Technol Biotechnol. 2014;90:1364-79.

6. Tuck CO, Perez E, Horvath IT, Sheldon RA, Poliakoff M. Valorization of biomass: deriving more value from waste. Science. 2012;337:695-9.

7. Reis M, Albuquerque M, Villano M, Majone M. Mixed culture processes for polyhydroxyalkanoate production from agro-industrial surplus/wastes as feedstocks. In: Fava F, Agathos S, Young M, editors. Comprehensive biotechnology. Amsterdam: Elsevier; 2011. p. 669-83.

8. Salehizadeh H, Van Loosdrecht MCM. Production of polyhydroxyalkanoates by mixed culture: recent trends and biotechnological importance. Biotechnol Adv. 2014;22:261-79.

9. Ivanov V, Stabnikov V, Ahmed Z, Dobrenko S, Saliuk A. Production and applications of crude polyhydroxyalkanoate containing bioplastic from the organic fraction of municipal solid waste. Int J Environ Sci Tech. 2015;12:725-38

10. Duque AF, Oliveira CSS, Carmo ITD, Gouveia AR, Pardelha F, Ramos AM, Reis MAM. Response of a three-stage process for PHA production by mixed microbial cultures to feedstock shift: impact on polymer composition. New Biotechnol. 2013;31:276-88.

11. Colombo B, Pepè Sciarria T, Reis M, Scaglia B, Adani F. Polyhydroxyalkanoates (PHAs) production from fermented cheese whey by using a mixed microbial culture. Bioresour Technol. 2016;218:692-9.

12. Dionisi D, Carucci G, Petrangeli Papini M, Riccardi C, Majone M, Carrasco F. Olive oil mill effluents as a feedstock for production of biodegradable polymers. Water Res. 2005;39:2076-84

13. Lee WS, Chua ASM, Yeoh HK, Nittami T, Ngoh GC. Strategy for the biotransformation of fermented palm oil mill effluent into biodegradable polyhydroxyalkanoates by activated sludge. Chem Eng J. 2015;269:288-97.

14. Tamis J, Luzkov K, Jiang Y, Van Loosdrecht MCM, Kleerebezem R. Enrichment of Plasticicumulans acidivorans at pilot-scale for PHA production on industrial wastewater. J Biotechnol. 2014;192:161-9.

15. Rhu DH, Lee WH, Kim JY, Choi E. Polyhydroxyalkanoate (PHA) production from waste. Water Sci Technol. 2003:48:221-8.

16. Zhang $\mathrm{M}, \mathrm{Wu} \mathrm{H}$, Chen $\mathrm{H}$. Coupling of polyhydroxyalkanoate production with volatile fatty acid from food wastes and excess sludge. Process Saf Environ. 2014;92:171-8

17. Amulya K, Jukuri S, Venkata Mohan S. Sustainable multistage process for enhanced productivity of bioplastics from waste remediation through aerobic dynamic feeding strategy: process integration for up-scaling. Bioresour Technol. 2015;188:231-9.

18. Korkakaki E, Mulders M, Veeken A, Rozendal R, Van Loosdrecht MC, Kleerebezem R. PHA production from the organic fraction of municipal solid waste (OFMSW): overcoming the inhibitory matrix. Water Res. 2016;96:74-83.

19. Pognani M, D'Imporzano G, Scaglia B, Adani F. Substituting energy crops with organic fraction of municipal solid waste for biogas production at farm level: a full-scale plant study. Process Biochem. 2009;44:817-21.

20. Massaccesi L, Sordi A, Micale C, Cucina M, Zadra C, Di Maria F, Gigliotti G. Chemical characterization of percolate and digestate during the hybrid solid anaerobic digestion batch process. Process Biochem. 2013:48:1361-7.
21. Di Maria F, Gigliotti G, Sordi A, Micale C, Zadra C, Massaccesi L. Hybrid solid anaerobic digestion batch: biomethane production and mass recovery from the organic fraction of solid waste. Waste Manag Res. 2013;31:869-73.

22. Serafim LS, Lemos PC, Oliveira RF, Reis MAM. Optimization of polyhydroxybutyrate production by mixed cultures submitted to aerobic dynamic feeding conditions. Biotechnol Bioeng. 2004;87:145-60.

23. Valentino F, Beccari M, Fraraccio S, Zanaroli G, Majone M. Feed frequency in a Sequencing Batch Reactor strongly affects the production of polyhydroxyalkanoates (PHAs) from volatile fatty acids. New Biotechnol. 2014;31:264-75.

24. Pardelha F, Albuquerque MGE, Reis MAM, Dias JML, Oliveira R. Flux balance analysis of mixed microbial cultures: application to the production of polyhydroxyalkanoates from complex mixtures of volatile fatty acids. J Biotechnol. 2012;162:336-45.

25. Kulkarni SO, Kanekar PP, Nilegaonkar SS, Sarnaik SS, Jog JP. Production and characterization of a biodegradable poly (hydroxybutyrate-cohydroxyvalerate) (PHB-Co-PHV) copolymer by moderately haloalkalitolerant Halomonas campisalis MCM B-1027 isolated from Lonar Lake, India. Bioresour Technol. 2010;101:9765-71.

26. The U.S. Department of Agriculture and The U.S. Composting Council. Test Methods for the Examination of Composting and Compost (TMECC). Houston: Edaphos Int; 2001.

27. Lahav O, Morgan B, Loewenthal RE. Rapid, simple and accurate method for measurement of VFA and carbonate alkalinity in anaerobic reactors. Environ Sci Technol. 2002;36:2736-3274.

28. Valentino F, Riccardi C, Campanari S, Pomata D, Majone M. Fate of $\beta$-hexachlorocyclohexane in the mixed microbial cultures (MMCs) threestage polyhydroxyalkanoates (PHA) production process from cheese whey. Bioresour Technol. 2015;192:304-11.

29. Albuquerque MGE, Torres CAV, Reis MAM. Polyhydroxyalkanoate (PHA) production by a mixed microbial culture using sugar molasses: effect of the influent substrate concentration on culture selection. Water Res. 2010;44:3419-33.

30. Reddy MV, Mohan SV. Effect of substrate load and nutrients concentration on the polyhydroxyalkanoates (PHA) production using mixed consortia through wastewater treatment. Bioresour Technol. 2012:114:573-82

31. Din MdMF, Mohanadoss P, Ujang Z, Van Loosdrecht MCM, Yunus SM, Chelliapan S, Zambare V, Olsson G. Development of Bio-PORec system for polyhydroxyalkanoates (PHA) production and its storage in mixed cultures of palm oil mill effluent (POME). Bioresour Technol. 2012;124:208-16.

32. Waller JL, Green PG, Loge FJ. Mixed-culture polyhydroxyalkanoate production from olive oil mill pomace. Bioresour Technol. 2012;120:285-9.

33. Moita R, Freches A, Lemos PC. Crude glycerol as feedstock for polyhydroxyalkanoates production by mixed microbial cultures. Water Res. 2014;58:9-20

34. Omar FN, Rahman NA, Hafid HS, MumtazT, Yee PL, Hassan MA. Utilization of kitchen waste for the production of green thermoplastic polyhydroxybutyrate (PHB) by Cupriavidus necator CCGUG 52238. Afr J Microbiol Res. 2011;5:2873-9.

35. Hafuka A, Sakaida K, Satoh H, Takahashi M, Watanabe Y, Okabe S. Effect of feeding regimens on polyhydroxybutyrate production from food wastes by Cupriavidus necator. Bioresour Technol. 2011;102:3551-3.

36. Zhang L, Tang H, Hou G, Shen Y, Deng F. The domain structure and mobility of semi-crystalline poly(3-hydroxybutyrate) and poly(3hydroxybutyrate-co-3-hydroxyvalerate: a solid-state NMR study. Polymer. 2007;48:2928-38.

37. Allen AD, Anderson WA, Ayorinde FO, Eribo BE. Biosynthesis and characterization of copolymer poly (3HB-co-3HV) from saponified Jatropha curcas oil by Pseudomonas oleovorans. J Ind Microbiol Biotechnol. 2010;37:849-56.

38. Gholami A, Mohkam M, Rasoul-Amini S, Ghasemi Y. Industrial production of polyhydroxyalkanoates by bacteria: opportunities and challenges. Minerva Biotecnol. 2016:28:59-74. 